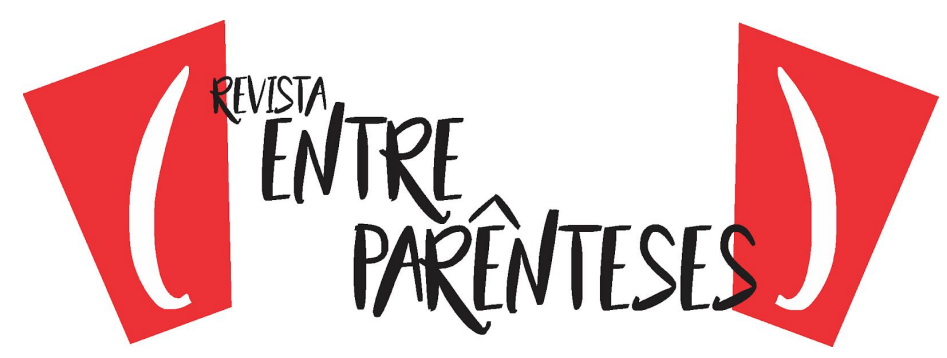

\title{
O FEMINISMO NEGRO EM PURPLE HIBISCUS, DE CHIMAMANDA NGOZI ADICHIE
}

\author{
Sanmanth do Nascimento Araújo ${ }^{1}$ \\ Universidade Estadual do Piauí \\ (sanmanth@yahoo.com.br) \\ Prof. Dra. Algemira de Macedo Mendes ${ }^{2}$ \\ Universidade Estadual do Piauí \\ (algemiramendes95@gmail.com)
}

\begin{abstract}
Resumo: Assim como em outras obras de Chimamanda Ngozi Adichie, Purple Hibiscus é um romance que possibilita trazer à tona diversas discussões acerca do tema da ancestralidade, do sujeito colonizado, da negritude e do papel da mulher na sociedade africana. Percebendo que o feminismo é um aspecto muito presente na obra da escritora, busca-se neste trabalho mostrar a complexidade identitária das personagens citadas sob a ótica do feminismo negro, tendo como objetivo principal apresentar de que forma as personagens do romance não foram reduzidas a estereótipos maniqueístas, representação tão presente na literatura ocidental.
\end{abstract}

Palavras-chave: Feminismo; Identidade; Feminismo Negro; Chimamanda Ngozi Adichie.

\section{BLACK FEMINISM IN PURPLE HIBISCUS, BY CHIMAMANDA NGOZI ADICHIE}

Abstract: As in other works written by Chimamanda Ngozi Adichie, Purple Hibiscus is a novel that can bring to the surface a variety of discussions about ancestry, colonized people, blackness and the women's role inside the African society. Noticing that feminism is a very present issue in the writer's work, we aim to show the complexity of the characters' identity mentioned previously from the perspective of black feminism, having as the main goal to show that the characters in the novel were not reduced to manicheistic stereotypes, a representation that is so current in the western literature.

Keywords: Feminism; Identity; Black Feminism; Chimamanda Ngozi Adichie.

\section{FEMINISMO NEGRO EN PURPLE HIBISCUS, POR CHIMAMANDA NGOZI ADICHIE}

Resumen: Al igual que en otros trabajos de Chimamanda Ngozi Adichie, Purple Hibiscus es una novela que saca a la luz varias discusiones sobre el tema de la ascendencia, el tema del colonizado, de la negritud y del papel de la mujer en la sociedad africana. Al darse cuenta de que el feminismo es un aspecto muy presente en el trabajo de la escritora, este artículo busca mostrar la complejidad de la identidad de los personajes mencionados desde la perspectiva del feminismo negro, con el objetivo

\footnotetext{
${ }_{1}^{1}$ Mestra do Programa de Pós-graduação em Letras pela Universidade Estadual do Piauí - UESPI, dentro da linha de pesquisa Literatura, Memória e Gênero.

2 professora Doutora Algemira de Macedo Mendes que possui Doutorado em Letras pela Pontifícia Universidade Católica do Rio Grande do Sul com estágio de doutorado sanduíche em Coimbra - PT. Pós-doutora em Literaturas Africanas de Língua Portuguesa pela Universidade de Lisboa. É professora associada da Universidade Estadual do Piauí - UESPI e Universidade Estadual do Maranhão - UEMA.
} 


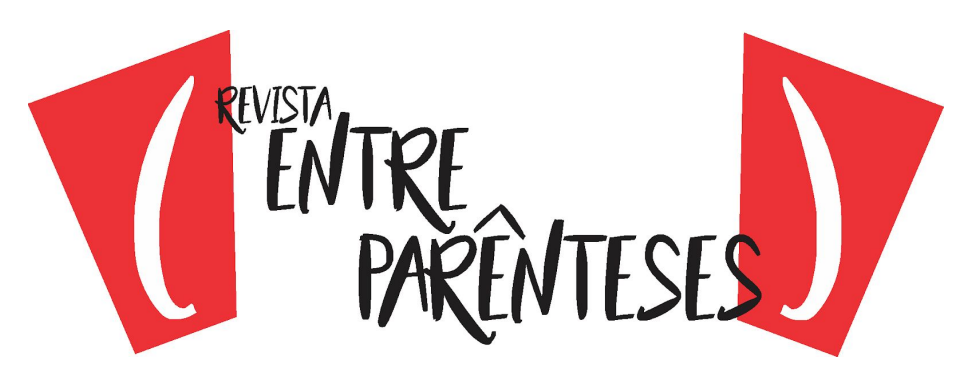

principal de presentar como los personajes de la novela no se redujeron a estereotipos maniquíes, representación tan presente en la literatura occidental.

Palabras claves: Feminismo; Identidad; Feminismo Negro; Chimamanda Ngozi Adichie.

Dentre os grupos subjugados ao longo da história, observa-se que as mulheres e sua literatura propõem um resgate de grande importância para o estudo das relações ligadas a opressão não só de gênero, mas também de classe e raça. Como aponta Zinani (2013), a partir do momento que a mulher passou a se apropriar do discurso e passou a contar sua história, começou-se a se questionar os padrões estereotipados do papel da mulher dentro da sociedade.

A constituição do sujeito feminino é um processo com raízes históricas que implica transformações relevantes na sociedade, uma vez que a mudança da mulher acarreta modificações nos papéis sociais que deixam de ser fixos e definidos, tornando-se abertos e indeterminados. Essa transição produz ambiguidade de comportamento e incerteza quanto à identidade [...]. (ZINANI, 2013, p. 55)

Assim, constituindo uma nova geração de escritoras africanas, que tem como objetivo falar sobre os conflitos étnicos da África e questionar a construção histórica de seu passado feita pelos europeus, Chimamanda Ngozi Adichie vem sendo aclamada pelos leitores e pela crítica ao redor do mundo. Já conquistou prêmios como Orange Prize, BBC Short Story Awards, O. Henry, Beyond Margin Awards, Prêmio Commonwealth Writers, National Book Critics Circle Award, Anisfield-Wolf Book Award.

O feminismo em Chimamanda Ngozi Adichie é aberto e explícito em todos os seus discursos. Em suas produções ficcionais, isso não se dá de forma diferente. Com três romances publicados até agora, Adichie mostra-se preocupada em revelar a multiplicidade de identidades que as mulheres africanas podem ter e 


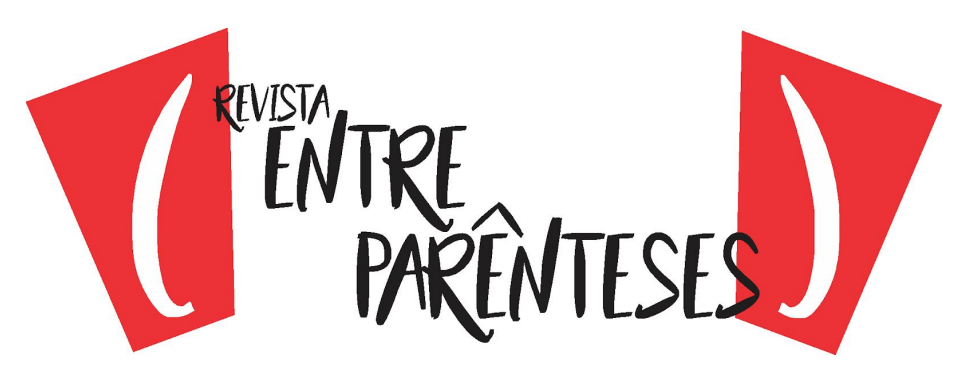

como diferentes aspectos da vida cotidiana, política e social podem influenciar nessa construção da identidade.

A autora em questão vem sendo muito trabalhada nas universidades, mas, por ela estar em ascensão, esses trabalhos ainda são recentes. Algumas dissertações publicadas no Brasil como Por uma modernidade própria: o transcultural nas obras Hibisco Roxo, de Chimamanda Ngozi Adichie, e o Sétimo Juramento, de Paulina Chiziane, de Rafaela Cristina Alves Teotônio (2013), defendida pela UEPB e Gênero e Nação na Ficção de Chimamanda Ngozi Adichie, de Roberta Mara Resende (2013), defendida pela UFSJ, servem de exemplos de trabalhos acerca da problemática a ser abordada neste projeto. Temos ainda a dissertação escrita por Fernanda de Oliveira Muller (2017), defendida pela UnB, intitulada como $O$ florescer das vozes na tradução de Purple Hibiscus, de Chimamanda Ngozi Adichie que oferece um interessante aporte teórico no que diz respeito as estratégias linguísticas utilizada pela escritora e como a tradutora da edição brasileira agiu em relação a elas. No estado do Piauí, temos a dissertação Ana Cláudia Oliveira Neri Alves (2018), defendida pela Uespi e intitulada como Identidade em trânsito: a experiência diaspórica de Ifemelu em Americanah, de Chimamanda Ngozi Adichie. Nessa dissertação.

Ainda dentre essas pesquisas acadêmicas, destaca-se a dissertação escrita por Natalia Telega-Soares (2014), intitulada " $E$ ouviram-se as vozes de mulheres africanas..." O feminismo africano e a escrita de Chimamanda Ngozi Adichie, pela Universidade Nova de Lisboa. Nessa dissertação, a autora discorre sobre os diferentes movimentos criados pelas mulheres negras que não se viam representadas pelo movimento feminista e de que forma esses movimentos aparecem na escrita de Adichie.

Sobre a questão do feminismo negro, não existem muitas obras publicadas acerca do tema no Brasil, mas há muita referência em outras línguas. No Brasil, tem-se o mais recente lançamento de Mulheres, raça, classe de Angela Davis 


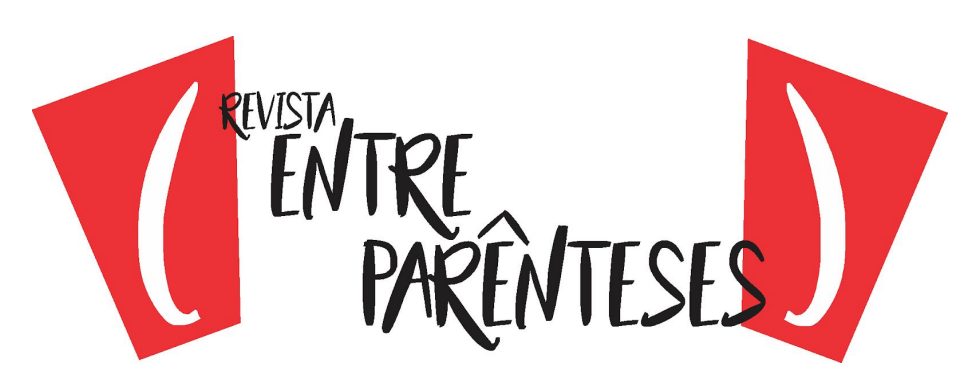

(2016). Em outros idiomas fazem-se de extrema importância para a pesquisa textos como Gender in African Women's Writing de Nfah-Abenuyi (1997) e Theorizing Black Feminisms, de James \& Busia (1993).

Seu primeiro romance e objeto de estudo deste trabalho, publicado em 2003, Purple Hibiscus, ganhou o Hurston-Wright Legacy Award 2004, como Melhor primeiro livro, Commonwealth Writer's Prize 2005, melhor primeiro livro - África, Commonwealth Writer's Prize 2005, melhor primeiro livro, foi nominado para o Orange Prize for Fiction, 2004, Booker Prize 2004, Yalsa (Young Adult Library Services Association) 2004 e John Llewellyn Thys Prize 2004/2005.

Em Purple Hibiscus, temos diversos temas que podem ser abordados sob a luz das mais diversas áreas, como colonialismo, religião, gênero e política. Nesse romance, Adichie nos apresenta um chefe de família colonizado e agressivo, uma esposa aparentemente passiva, filhos que são obrigados a se sujeitar às crenças e desejos do pai, e uma tia transgressora.

Beatrice é humilhada, silenciada e agredida pelo marido, Eugene, e é a personagem chave que vai pôr fim a toda sua tirania e dar liberdade a todos que 0 cercam. Tia Ifeoma é viúva, professora universitária e não tem medo de expressar suas opiniões. Cria seus três filhos sozinha em meio a dificuldades financeiras, mas se recusa a aceitar ajuda de Eugene, pois não quer Ihe dever ainda mais. Ifeoma não tem medo de enfrentar o irmão ou de discordar da cultura igbo no que dizia respeito às mulheres e seus direitos. Ao coordenar a rotina da casa, todos têm afazeres domésticos, não só Amaka, como também os filhos homens. Em seus diálogos com Beatrice, temos acesso às ideias e conviç̧ões desse outro exemplo de mulher. A dinâmica das duas personagens cria uma representação da mulher africana. Beatrice mesmo aparentando ser dócil, mostra-se forte e rebelde, capaz de fazer o inesperado, enquanto Ifeoma é uma mulher marcante e corajosa.

Percebemos como as personagens femininas de Adichie são mulheres fortes, que percorrem um crescimento pessoal e um amadurecimento visível durante 


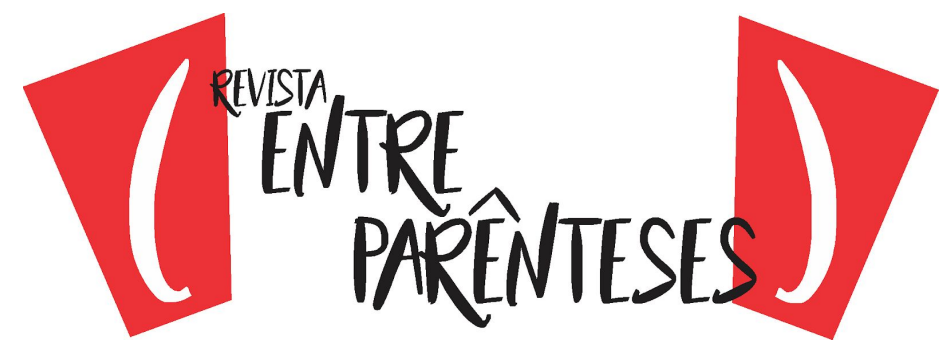

a narrativa, justificando assim toda a atenção que a autora vem recebendo da crítica e da mídia. Seus romances e palestras vêm sendo responsável pela aproximação de novos leitores à literatura africana e à temas como colonialismo e feminismo.

Como voz fundamental na narrativa de Purple Hibiscus temos Kambili, uma menina entrando na adolescência, caracterizada como uma narradora autodiegética. Ela nos aproxima da sua história e de sua família com um discurso simples, porém longe de ser simplista. Observamos as contradições existentes na sua relação com seu pai, a submissão da mãe e a elevada carga emocional compartilhada com o irmão.

De acordo com Fernanda de Oliveira Muller, em sua dissertação $O$ despertar das vozes na tradução de Purple Hibiscus, pela UnB, em 2017, podemos qualificar o romance citado como um romance de formação. Isso porque percebemos notoriamente um desenvolvimento emocional, moral, físico e psicológico em Kambili durante todo o romance. O seu amadurecimento é perceptível em todos os seus questionamentos, ações e mudanças de atidude. Segundo a autora:

Purple hibiscus pode ser classificado como um Bildungsroman ou "romance de formação": ao longo da história, a personagem-narradora Kambili transforma-se, deixando de ser uma menina ingênua e amedrontada para se tornar uma jovem mulher que tem voz e pensamento próprios. (MULLER, 2017, p. 40)

A conquista dessa voz e pensamentos próprios se dá com a mudança de espaço que ocorre duas vezes no romance. A ação passa-se nas cidades de Enugu e Nsukka, no contexto pós-república de Biafra, nos anos de 1960, tendo como pano de fundo uma Nigéria cheia de conflitos políticos e instabilidade econômica. A separação de Biafra da Nigéria culminou em uma sequência de batalhas que resultaram em uma guerra civil que marcou a história da Nigéria. Alguns personagens como Eugene e tia Ifeoma são afetados diretamente por essas 


\section{("iifres}

mudanças políticas, ditando como eles se comportam e influenciando diretamente outros personagens, que é o caso de Kambili.

Inicialmente, as mulheres africanas não se identificavam com 0 feminismo, pois elas não se reconheciam com as categorias já estabelecidas e não viam suas lutas sendo batalhadas, nem suas bandeiras levantadas. Para elas, os problemas que as mulheres brancas e ocidentais acusavam de agente causador de toda a situação precária da mulher, não era o mesmo para elas.

Os problemas enfrentados pelas mulheres brancas como supremacia masculina, falta de oportunidade de empregos, maternidade e domesticidade compulsória tornaram-se os problemas centrais de todas as mulheres. $\mathrm{O}$ que acontecia com as mulheres brancas durante a chamada "Primeira onda do feminismo" passou a ser o problema universal de todas as mulheres. Essa chamada "primeira onda do feminismo", que aconteceu durante o século XIX e início do século XX, preocupava-se com a situação da mulher na sociedade de forma política. A busca por mais espaço, direitos e oportunidades foi o foco central do movimento. Lutava-se por mais direitos no casamento, já que como as mulheres não tinham direitos a propriedade, elas precisavam casar para viver e assim aceitavam quaisquer condições que Ihes fossem oferecidas. Porém, muitas estudiosas africanas argumentavam que a mulher branca, mesmo oprimida em muitas esferas de sua vida, ainda se encontrava em um grau de superioridade da mulher negra. Estas não possuíam empregos, nem direito a voto ou a vida acadêmica, não por serem mulheres, mas por serem negras. Era uma condição que afetava homens e mulheres negros, tornando-os não rivais ou inimigos, como as feministas brancas da "Primeira onda" percebiam, mas companheiros na luta contra o preconceito racial.

Observa-se então que a opressão sofrida pelas mulheres negras não possuía somente uma origem. A opressão feminina não era causada somente pelo patriarcado. Existia a raiz econômica, já que tanto as mulheres como os homens negros eram responsáveis pelos trabalhos degradantes da sociedade recebendo 


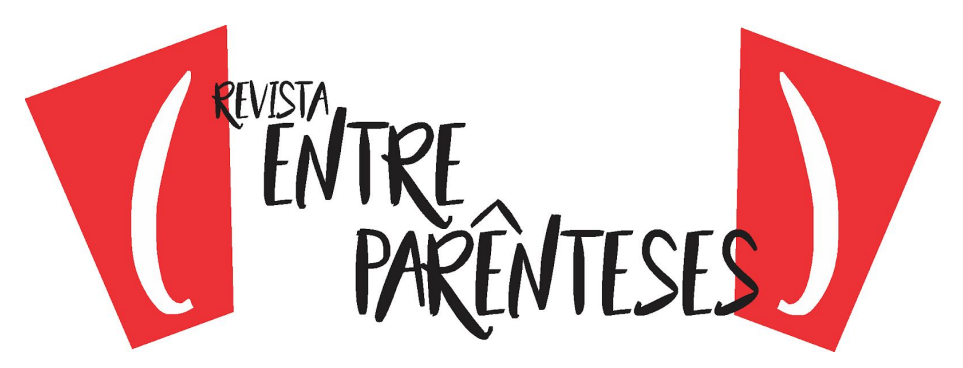

salários baixos; a opressão política, pois direito a cargos públicos e direito ao voto eram negados duplamente; e a opressão da imagem, já que as mulheres negras eram estereotipadas até pelas mulheres brancas. Não existia igualdade entre homens e mulheres, mas também não existia entre as próprias mulheres. Assim, surgiu a necessidade de movimentos de nomenclatura diferenciada que lutassem pelos direitos das mulheres negras.

A escritora e ativista americana Alice Walker (1972) foi a primeira a aparecer com um termo que buscasse atender as necessidades das mulheres negras. Em seu conto "Coming Apart", Walker traz pela primeira vez o termo Womanism. A autora afirma ter tirado o termo de uma expressão do sul dos Estados Unidos, onde as pessoas dizem a uma criança que está agindo de forma escandalosa ou corajosa que ela "está agindo como uma mulher"³ (WALKER, 1972, p. 12).

Em seguida, no prólogo de In Search of Our Mothers' Gardens, Walker apresenta as definições do termo cunhado por ela. Nesse texto, ela menciona o livro Um teto todo seu, de Virginia Woolf, onde a autora afirma que para uma mulher escrever um livro ela precisa de um cômodo com chave e fechadura e dinheiro suficiente para se sustentar. Walker, por sua vez, menciona Phillis Wheatley, poeta e escrava do século XVIII. A autora questiona como Wheatley conseguiria possuir tudo isso, se não tinha direito a si própria, se não se pertencia. Mesmo com seu talento para poesia, ela trabalhou até a exaustão por sua segurança e de seus filhos pequenos, até seu corpo não aguentar mais. Logo, a autora apresenta que para ser uma womanist bastava ser uma feminista negra ou uma mulher de cor. O termo Womanism dizia respeito à mulher que ama a história e o poder das mulheres, principalmente por estar entranhado nele, reconhece que os homens fazem parte da vida das mulheres como filhos, amores ou membros da família.

\footnotetext{
${ }^{3}$ Acting womanish (Tradução nossa)
} 


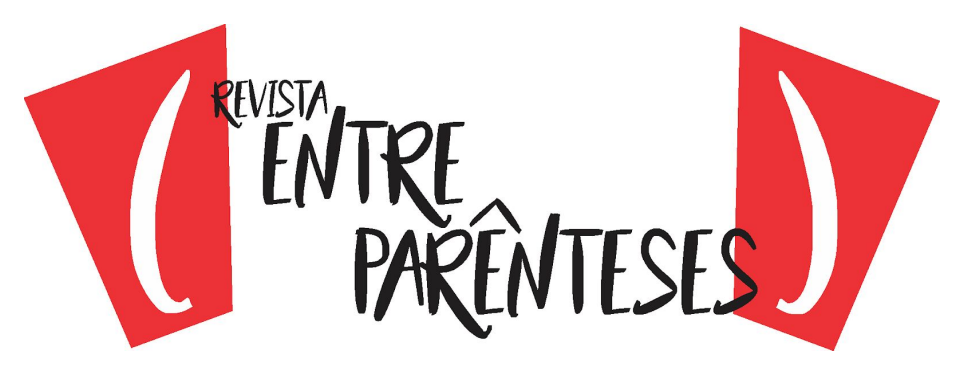

Se opondo especificamente à segunda onda do feminismo, que ainda via o homem como seu principal rival. Womanism reconhece as diferentes formas de opressão existentes e como cada mulher, em sua individualidade, luta para fugir de cada uma delas. Não é sua cor que define o seu tipo de feminismo, mas a sua cor serve como uma lente para enxergar sua própria feminilidade. Coleman (2013), em seu texto Ain't I a feminist too?, faz um resumo das definições dadas por Alice Walker em outros ensaios sobre Womanism.

1. From womanish (Opp. of "girlish," i.e., frivolous, irresponsible, not serious.) A black feminist or feminist of color. Interested in grownup doings. Acting grown-up. Being grown-up. Responsible. In charge. Serious.

2. Also: a woman who loves other women, sexually and/or nonsexually. Appreciates and prefers women's culture, women's emotional flexibility (values tears as natural counterbalance of laughter), and women's strength. Sometimes loves individual men, sexually and/or nonsexually. Committed to survival and wholeness of entire people, male and female. Not a separatist, except periodically, for health. Traditionally universal. Traditionally capable.

3. Loves music. Loves dance. Loves the moon. Loves the Spirit. Loves love and food and roundness. Loves struggle. Loves the Folk. Loves herself. Regardless.

4. Womanist is to feminist as purple to lavender. ${ }^{4}$

Seguindo a mesma linha de pensamento, a crítica literária Chikwenye Okonjo Ogunyemi (1988) já usa o termo African Womanism. Concordando com Alice Walker, a nigeriana afirma que este é um movimento que deseja a independência

\footnotetext{
${ }^{4} 1$ - De womanism: (opp. Feminino, ie, frívolo, irresnponsável, não sério). Uma feminista negra ou feminista de cor. Interessada em coisas adultas. Age como adulta. É adulta. Responsável. No comando. Séria.

2 - Também: uma mulher que ama outras mulheres, sexualmente e/ou não sexualmente. Aprecia e prefere a cultura das mulheres, sua flexibilidade emocional (valoriza lágrimas contrabalanceado com risadas), e a força das mulheres. As vezes ama homens individualmente, sexualmente e/ou não sexualmente. Comprometida com a sobrevivência e plenitude de todas as pessoas, homens ou mulheres. Não é separatista, exceto periodicamente, pela saúde. Tradicionalmente universal. Tradicionalmente capaz.

3 - Ama música. Ama dançar. Ama a lua. Ama o Espírito. Ama, ama e comida e circularidade. Ama o conflito. Ama o popular. Ama a si mesma. Indiferente.

4 - Womanis está para o feminismo como o roxo está para o lavanda. (Tradução nossa)
} 


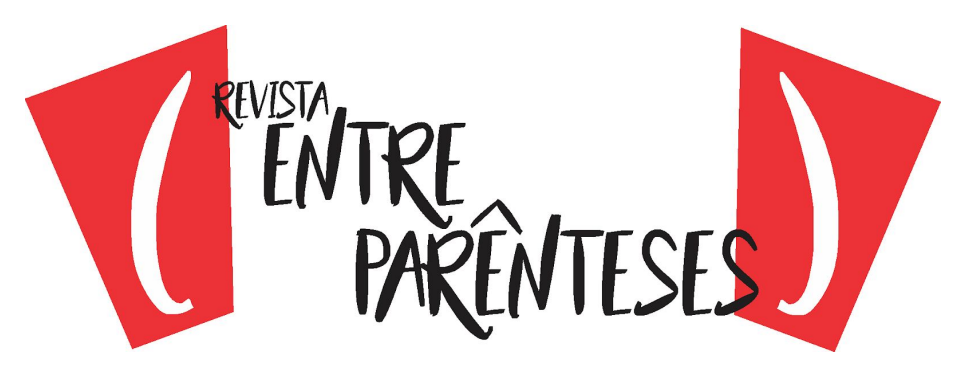

das mulheres, como o feminismo. No entanto, ele é centrado nas mulheres africanas negras e nos seus interesses. Para Ogunyemi, deve-se ter cuidado com as relações com o feminismo ocidental pela falta de representatividade. Ela acusa muitas mulheres de simpatizarem com o movimento das mulheres brancas ocidentais, enfraquecendo o African Womanism. A crítica defende que toda a filosofia das mulheres africanas deve incluir consciência de questões sexuais, questões raciais, econômicas e políticas.

Womanism is black centered, it is accommodation. It believes in the freedom and independence of women like feminism; unlike radical feminism, it wants meaningful union between black women and black men and black children and will see to it that men begin to change from their sexual stand. (OGUNYEMI, 1988, p. 65)

Ogunyemi, ainda busca se afastar do Womanism afro-americano, cunhado por Alice Walker, pois para ela, somente as mulheres africanas sabem de suas necessidades e dificuldades. Mesmo percebendo que as mulheres afro-americanas sabem que o que as aflige é mais do que sexo ou gênero, a autora afirma que se deve celebrar as raízes negras africanas e seus ideais. É possível perceber um certo extremismo nas recomendações de Ogunyemi, o que facilita a não identificação de muitas mulheres, por estas estarem buscando liberdade de pensamento e não mais amarras.

A partir daí surgiram outros movimentos na tentativa de abarcar a problemática da mulher africana. Dialogando de uma forma mais radical com Walker e Ogunyemi, a afro-americana Cleonora Hudson-Weens, cunhou o termo Africana Womanism. De acordo com ela, o Africana Womanism nasceu em solo africano, então é focado nas dores, necessidades e desejos das mulheres africanas, mas

\footnotetext{
${ }^{5}$ Womanism é centrado nas questões negras, é acomodação. Acredita na liberdade e independência das mulheres como o feminismo; mas diferentemente do feminismo radical, quer uma união significativa entre mulheres, homens e crianças negras e vai perceberá com isso que os homens vão começar a mudar sua posição. (Tradução nossa)
} 


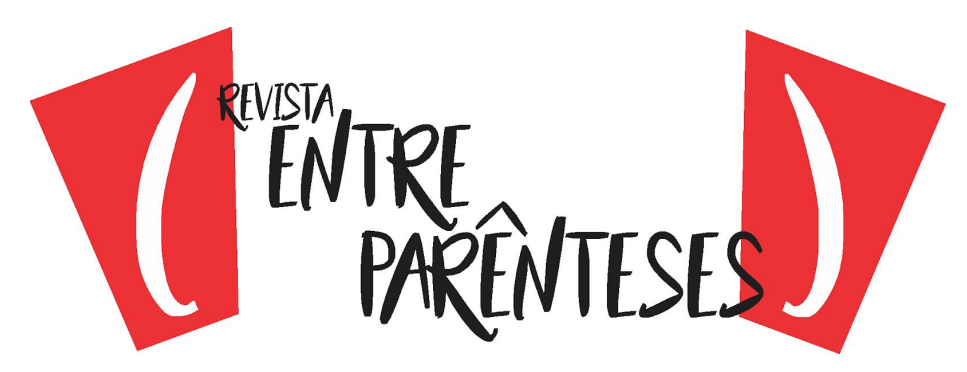

compreende que com a escravização muitas irmãs deixaram suas terras e precisavam ser representadas, bem como suas descendentes. A autora afirma que se deve eliminar completamente qualquer influência racista de suas vidas antes de qualquer coisa e não se deve tolerar nenhuma forma de subjugação feminina. Para Hudson-Weens, o principal inimigo não é o sexismo, mas sim o racismo e o classismo. Assim, faz-se impossível ter alguma ligação entre as mulheres africanas e o feminismo ocidental, por causa da história de escravidão que aconteceu no Ocidente. De acordo com a autora, também era necessário que houvesse ruptura total com o feminismo, sendo acusadas de traição as mulheres que de alguma forma colaborassem com o discurso feminista ocidental.

Em seguida, surgiu o Negofeminism que diz respeito ao feminismo da negociação. A acadêmica nigeriana Obioma Nnaemeka cunhou esse termo após observações e estudos possibilitados pela universidade. De acordo com Nnaemeka (2003), o Negofeminism busca saber quando ter o equilíbrio de verificar o que advém do patriarcado ou não e, ainda, quando e pelo que lutar. Para Nnaemeka, a diversidade de culturas dos povos africanos é inegável e esses valores devem ser respeitados e eles devem vir à tona para que sejam discutidos. A autora afirma também que não se deve fazer referências ao feminismo ocidental para buscar uma definição exata dos feminismos africanos, pois eles devem se preocupar com ambiente africano. Para a Nnaemeka, os feminismos africanos são pró-ativos e não reativos a um outro movimento. O Negofeminism, além de significar feminismo da negociação, também significa no ego feminism, ou seja, o bem-estar do coletivo e a valoração das diferentes culturas e estruturas existentes em todas as comunidades africanas devem ser levadas em consideração. A autora afirma que que não se trata apenas de dar ou somente de receber, mas de trocar.

In the foundation of shared values in many African cultures are the principles of negotiation, give and take, compromise, and balance. Here, negotiation has the double meaning of "give and take/exchange" and "cope with successfully/go around." African 


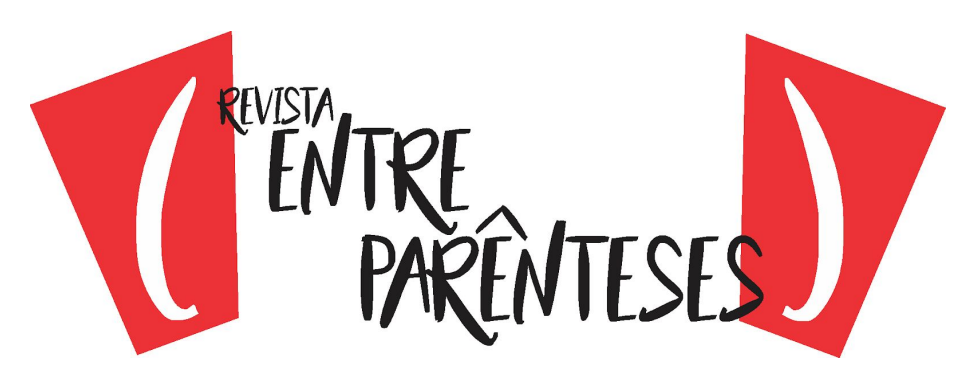

feminism (or feminism as I have seen it practiced in Africa) challenges through negotiations and compromise. It knows when, where, and how to detonate patriarchal land mines; it also knows when, where, and how to go around patriarchal land mines. In other words, it knows when, where, and how to negotiate with or negotiate around patriarchy in different contexts.(NNAEMEKA, 2014, p $377-378)^{6}$

Nnaemeka ressalta ainda que o Negofeminism tem vivido seus dias na teoria e na prática na África, devido ao comprometimento das mulheres africanas em construir uma sociedade harmoniosa. A acadêmica afirma que não interessa como o feminismo é chamado, no entanto, deve-se caminhar na jornada como um camaleão: com foco, cuidadoso, adaptável e aberto a mudanças e novas visões.

Buscando essa inclusão das mulheres na sociedade, tem-se ainda o Stiwanism, sigla para Social Transformation Including Women of Africa, que luta por uma maior participação das mulheres na vida política e social da comunidade. Ele é mais focado nas estruturas de opressão das mulheres, como elas reagem a essa opressão e como se comportam em frente essas estruturas. Para Molara Ogundipe-Leslie (1994), ativista e educadora nigeriana, o que as mulheres ocidentais consideram feminismo não é o mesmo que as mulheres africanas. A ativista confessa saber que muitos homens não concordarão, mas que as mulheres devem ajudar nas tomadas de decisões e incita todas a não lerem somente fofocas ou a seção para mulheres dos jornais, mas procurarem as notícias políticas ou que possuem alguma relevância para a comunidade de cada uma. Ogundipe-Leslie afirma que muitas ideias erradas são disseminadas e acabam trazendo confusão aos conceitos relacionados aos feminismos africanos e ao Stiwanism. Ela afirma, por exemplo, que as mulheres estão satisfeitas por serem quem são e não possuem a

\footnotetext{
${ }^{6} \mathrm{Na}$ fundação de valores compartilhados em várias culturas da África estão os princípios da negociação, dar e receber, se comprometer, e equilíbrio. Aqui, negociação tem duplo significado de "dar e receber/trocas" e "lidar com sucesso/dar a volta" feminismo africano (ou feminismo como eu tenho visto praticado na África) desafia através de negociações e compromisso. Sabe quando, onde e como detonar minas patriarcais; também sabe quando, onde e como dar a volta a minas patriarcais. Em outras palavras, sabe quando, onde e como negociar ou negociar ao redor do patriarcado em diferentes contextos. (Tradução nossa)
} 


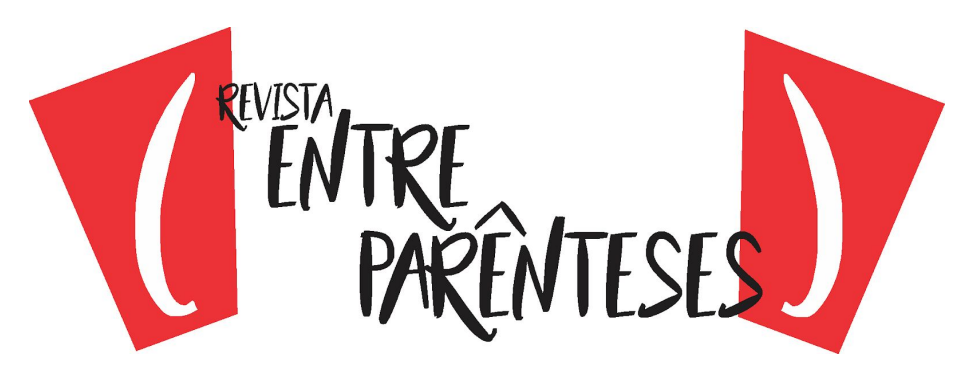

necessidade de uma vida sexual pública ou um ódio aos homens que acabe culminando em uma separação dos gêneros. De acordo com Ogundipe-Leslie, Stiwanism, bem como os outros feminismos africanos, não são movimentos separatistas e não é uma imitação do movimento feminista ocidental, é, na verdade, o resultado de reflexões e diálogos das mulheres africanas sobre os desafios enfrentados por elas diariamente. Stiwanism defende que as mulheres têm todo o potencial necessário para contribuírem com a construção do conhecimento dentro da sociedade. Com isso, ela nega sete aspectos errôneos que são difundidos sobre o Stiwanism.

1. It is not a cry for any kind of sexual orientation; sexual practice in Africa tends to be private

2. It is not the reversal of gender roles, 'gender' being defined simply as socially constructed identities and roles

3. It is not penis envy or gender envy, wanting to be a man like they say to us

4. It is not necessarily opposition to men. It argues that a woman's body is her inherent property

5. It is not dividing the genders

6. It is not parrotism of Western women's rhetoric

7. It is not opposed to African culture and heritage, but argues that culture is dynamically evolving and certainly not static; that culture should not be immobilised in time to the advantage of women

8. It is not opposed to African culture and heritage, but argues that culture is dynamically evolving and certainly not static; that culture should not be immobilised in time to the advantage of women. (OGUNDIPE-LESLIE, 1994, p. 219)

\footnotetext{
71 - Não é chorar por nenhum tipo de orientação sexual; a prática sexual na África tende a ser privada.

2- Não é reverter os papeis de gênero, "gênero" sendo definido simplesmente como identidades e papeis socialmente construídos

3 - Não é inveja do pênis ou de gênero, querer ser um homem como eles dizem que queremos

4 - Não é necessariamente oposição ao homem. Argumenta-se que o corpo de uma mulher é sua propriedade herdada.

5 - Não é dividir os gêneros

6 - Não é imitação do discurso das mulheres ocidentais
} 


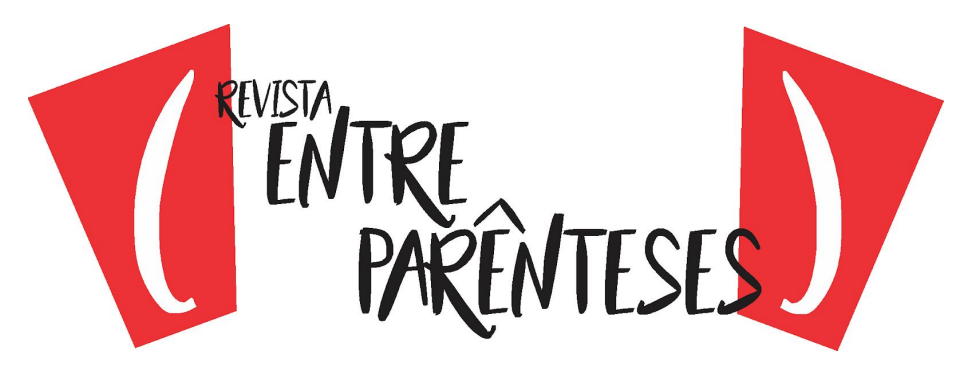

Ogundipe-Leslie, ao contrário de Ogunyemi ou Hudson-Weeds, não via o feminismo ocidental como inimigo, mas entendia a necessidade de um movimento com outra nomenclatura, para que assim pudesse ter uma quantidade maior de mulheres que se identificasse. Ela afirma que "many of the African female writers like to declare that they are not feminists, as if it were a crime to be a feminist" (OGUNDIPE-LESLIE, 1994, p. 211)

E, finalmente, temos o Motherism, termo cunhado por Catherine Acholonu. Ao contrário do que as feministas ocidentais defendiam, o lar e a maternidade não eram prisões para as mulheres africanas. Na verdade, era com a maternidade que elas atingiam um certo status dentro de algumas comunidades. $E$ isso era válido não só para as mulheres como para os homens também. Acholonu discute que enquanto para as mulheres brancas era possível e as vezes desejável ter poucos filhos ou nenhum, o mesmo não se aplicava as mulheres negras, pois era na maternidade que elas conseguiam a plenitude de seu ser.

An Afrocentric feminist theory, therefore, must be anchored on the matrix of motherhood which is central to African metaphysics and has been the basis of the survival and unity of the black race through the ages. Whatever Africa's role may be in the global perspective, it could never be divorced from her quintessential position as the Mother Continent of humanity, nor is it coincidental that motherhood has remained the central focus of African art, African literature (especially women's writing), African culture, African psychology, oral traditions, and empirical philosophy. Africa's alternative to Western feminism is MOTHERISM and Motherism denotes motherhood (...). The Motherist is the man or woman committed to the survival of Mother Earth as a hologrammatic entity. The weapon of Motherism is love, tolerance, service, and mutual cooperation of the sexes (...). The motherist writer $(\ldots)$ is not a sexist. The motherist male writer or artist

7 - Não se opõe a cultura africana ou herança, mas argumenta que a cultura está dinamicamente evoluindo e certamente não é estática; essa cultura não deveria ser imobilizada por dar vantagens as mulheres

8 - Não é uma escolha entre extrema pobreza de um lado ou separatismo cheio de ódio pelos homens do outro lado (Tradução nossa) 


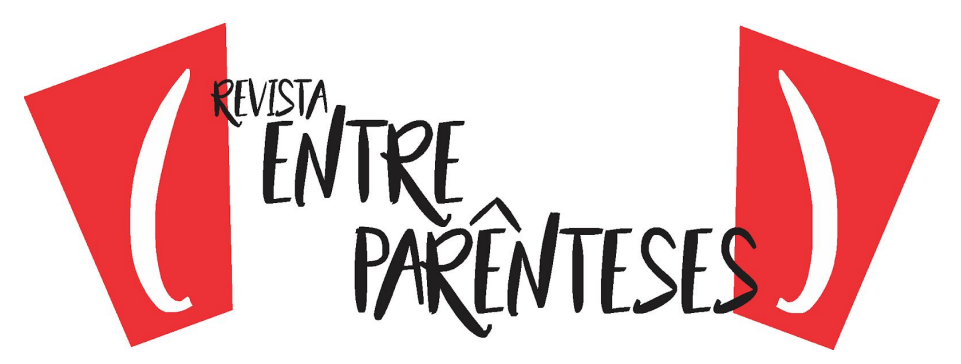

does not create his work from a patriarchal, masculinist, dominatory perspective. He does not present himself arrogant, all knowing self-righteous before his muse. (ACHOLONU in ARNDT, 1995 p. 112)

Percebe-se assim que as mulheres africanas, ampliando o discurso da segunda onda do feminismo, abriram um amplo leque de nomenclatura e discussões acerca da temática, propiciando que estudos relativos à proposta possam ser bem fundamentados. Dessa forma, percebe-se a variedade de pensamentos acerca do tema, a variedade de vozes que querem ser ouvidas. Sem essa mobilização e essa tentativa de buscar entender que amarras as prendiam e como vence-las, provavelmente as mulheres africanas continuariam a ser reféns do Ocidente.

No entanto, todos esses tipos de feminismos africanos ainda geram discussões e questionamentos. Tendo aparecido na década de 1990 e com a evolução do movimento feminista, muitas mulheres africanas não viram mais problema em serem chamadas de feministas, por perceberem que estavam começando a ser representadas e que as problematizações tinham saído do campo unicamente patriarcal. Chimamanda Ngozi Adichie, por exemplo, declarou-se abertamente feminista em sua palestra no TED "We should all be feminists", em dezembro de 2012. Isso fez com que mais mulheres voltassem a se identificar com o movimento e percebessem que seu espaço estava sendo conquistado.

\footnotetext{
${ }^{8}$ Uma teoria feminista afrocêntrica, portanto, deve estar ancorada na matriz da maternidade, que é central para a metafísica africana e tem sido a base da sobrevivência e unidade da raça negra através dos tempos. Seja qual for o papel de África na perspectiva global, nunca poderá ser divorciada da sua posição quintessencial como continente materno da humanidade, nem é coincidência que a maternidade tenha permanecido como o foco central da arte africana, literatura africana (especialmente escrita feminina), africana cultura, psicologia africana, tradições orais e filosofia empírica. A alternativa da África ao feminismo ocidental é o MOTHERISM e o motherism denota a maternidade (...). O Motherist é o homem ou a mulher comprometido com a sobrevivência da Mãe Terra como entidade holográfica. A arma do motherism é o amor, a tolerância, o serviço e a cooperação mútua entre os sexos (...). O escritor-motherist (...) não é sexista. O escritor ou artista motherist não cria sua obra de uma perspectiva patriarcal, masculinista e dominadora. Ele não se apresenta arrogante, conhecedor de tudo, moralista antes de sua musa (Tradução nossa)
} 


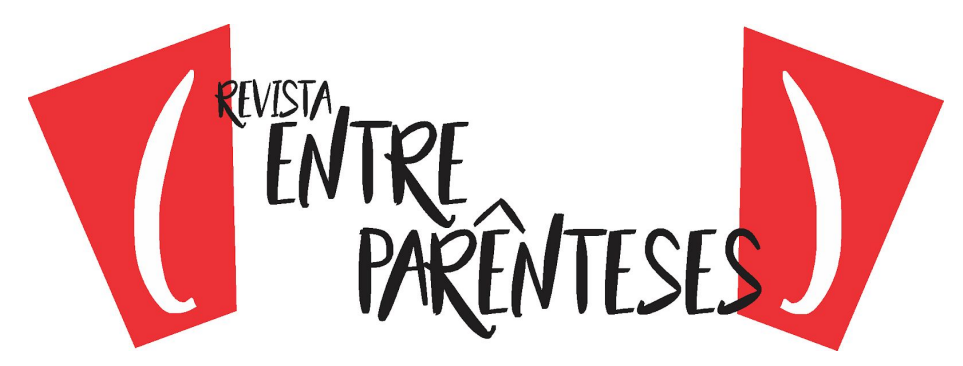

O romance é dividido em 4 partes, sendo elas: Breaking Gods (Palm Sunday), Speaking with our spirits (Before Palm Sunday), The pieces of Gods (After Palm Sunday) e A different silence (The present). Observamos que o fluxo temporal da narrativa está ligado ao tempo subjetivo da narradora, seu tempo psicológico. Os acontecimentos não são narrados na ordem temporal dos eventos. O romance já começa in media res, pois a primeira parte, Breaking Gods, trata-se do clímax do enredo, o auge do conflito dramático, com Jaja, irmão de Kambili, se negando a receber a comunhão e despertando a ira do pai. Esse evento fatídico ditou todos os acontecimentos decorrentes desse momento, pois como a própria personagem afirma "when Papa threw the missal at Jaja, it was not just the figurines that came tumbling down, it was everything" (ADICHIE, 2012, p. 15). A partir disso, na segunda parte, temos uma série de analepses, ou flashbacks, onde Kambili conta ao leitor os eventos que antecederam e justificam a primeira parte.

Eugene, pai de Kambili, é um rico industrial nigeriano. Católico fervoroso e colonizado, só fala em inglês, tem aversão a religiosidade africana e busca a purificação de seus familiares a todo instante. É um homem agressivo, violento e conservador, mas ao mesmo tempo é um grande benfeitor para os pobres de sua comunidade e é patrocinador de um dos jornais mais reacionários da Nigéria. Qualquer comportamento diferente do que Eugene julga correto, resultava em castigos a base de muita violência e crueldade, como lavar os pés dos filhos com água fervendo ou espancar Kambili até as costelas da filha quebrarem. Tudo com a justificativa de que se aquele fosse o dia do arrebatamento, os filhos deveriam estar purificados para que Deus pudesse salvá-los. Educados à base de castigos quando "transgrediam" alguma regra, os dois irmãos aprenderam a não questionar as instruções do pai e fazer o possível para agradá-lo.

\footnotetext{
9 “[...] quando Papa atirou o missal em Jaja, não foram apenas elas que se quebraram, mas todo o resto". (ADICHIE, 2011, p. 22)
} 


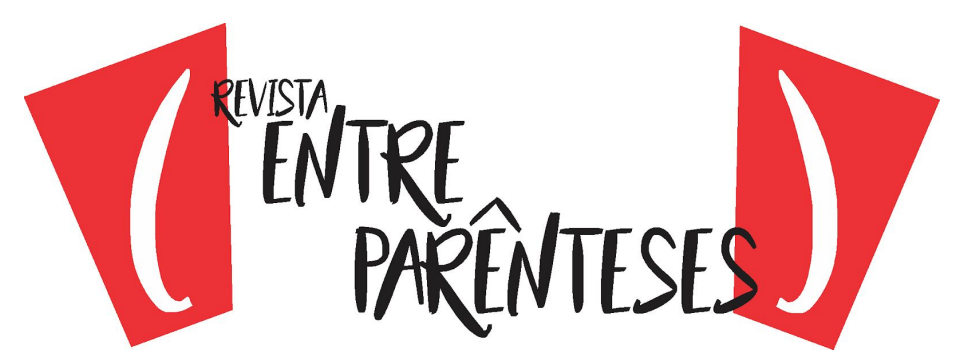

A violência de Eugene, no entanto, não se volta apenas para os filhos. Beatrice, mãe de Kambili, sofre rotineiramente com as sessões de violência doméstica do marido. No entanto, ela sofre calada. À primeira vista, percebemos Beatrice como uma mulher submissa, amedrontada e obediente à Eugene. Não existem evidências dessas violências, a não ser pelos barulhos graves vindos do quarto, os constantes abortos que Beatrice sofre ou um olho roxo que insiste em aparecer.

I was in my room after lunch, [...] when I heard the sounds. Swift, heavy thuds on my parentes' hand-carved bedroom door. I imagined the door had gotten stuck and Papa was trying to open it. If I imagined it hard enough, then it would be true. I sat down, closed my eyes, and started to count. Counting made it seem not that long, made it seem not that bad. Sometimes it was over before I even got to twenty. I was at nineteen when the sounds stopped. I heard the door open. Papa's gait on the stairs sounded heavier, more akward than usual. [...] Mama was slung over his shoulder like the jute sacks of rice his factory workers bought in bulk at the Seme border. (ADICHIE, 2003, p. 32-33).

Mesmo com toda essa violência, Beatrice sente-se grata ao marido por ser a única esposa. Com todos os seus abortos, causados pela brutalidade do marido, e com isso a constante impossibilidade de ter mais filhos, muitas mulheres são oferecidas a fim de aumentar a família, mas Eugene rejeita a todas. Com isso, Beatrice se sente em dívida com o marido, apesar de todos os abusos que lhes são impostos. Além disso, Beatrice admira os feitos de Eugene para a sociedade nigeriana, pois ele usa todo o seu poder e dinheiro para financiar campanhas contra

\footnotetext{
${ }^{10}$ Eu estava no meu quarto após o almoço [...] quando eu ouvi os sons. Pancadas pesadas e rápidas na porta talhada a mão do quarto dos meus pais. Imaginei que a porta estava emperrada e que Papa estivesse tentando abri-la. Se imaginasse aquilo sem parar, talvez virasse verdade. Eu me sentei, fechei os olhos e comecei a contar. Contar fazia o tempo passar um pouco mais rápido, fazia com que não fosse tão ruim. Às vezes, acabava antes de eu chegasse no vinte. Eu já estava no dezenove quando parou. Eu ouvi a porta se abrindo. Os passos de Papa na escada pareceram mais pesados, mais desajeitados que o normal. [...] Mama estava jogada sobre seu ombro como os sacos de juta cheios de arroz que os empregados da fábrica dele compravam aos montes na fronteira com Benin. (ADICHIE, 2011, p. 39)
} 


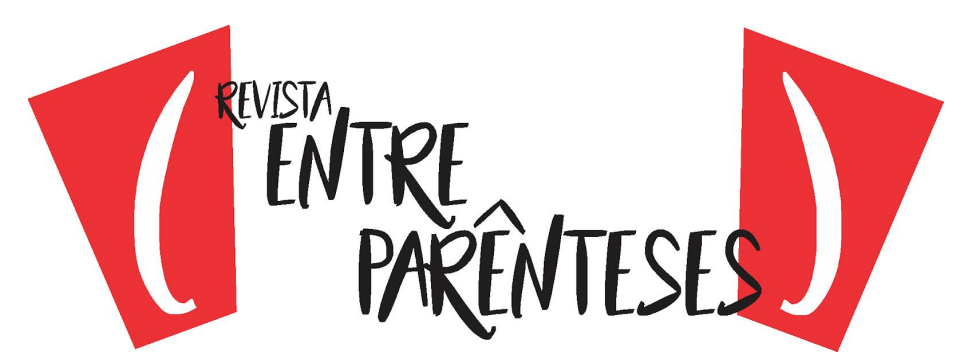

o governo totalitário em voga e patrocina várias ações sociais para os mais necessitados.

Do you know that Eugene pays the school fees of up to a hundred o four people? Do you know how many people are alive because of your brother? [...] Where would I go if I leave Eugene's house? Tell me, where would I go? [...] Do you know how many mothers pushed theis daughters at him? Do you know how many asked him to impregnate them, even, and not to bother paying a bride price? ${ }^{11}$ (ADICHIE, 2012, p. 250)

Sobre isso, sua cunhada, tia Ifeoma, a questiona e tenta faze-la perceber a fragilidade de seu argumento. Para Ifeoma, se Eugene tivesse largado a esposa ou tido um segundo casamento, a perda seria dele. Para ele, essa atitude do irmão de não seguir o conselho de arrumar uma outra esposa não configura nada de extraordinário. Ifeoma sabe da violência do irmão com a família e tenta, em várias passagens, incitar uma ação de Beatrice.

\footnotetext{
"Stop it, stop being so grateful, If Eugene had done that, he would have been the loser, not you".

"So you say. A woman with children e no husband, what is that?" "Me"

Mama shook her head. "You have come again, Ifeoma. You know what I mean. How can a woman live like that?" Mama's eyes had grown round, taking up more space on her face.

"Nwunye $m$, sometimes life begins when marriage ends"

"You and your university talk. Is this what you tell your students?" Mama was smiling. (ADICHIE, 2012, p. 75)
}

\footnotetext{
11 Você sabia que Eugene paga a mensalidade escolar de mais de cem pessoas? Sabe quantas pessoas estão vivas por causa do seu irmão? [...] Para onde eu vou se sair da casa de Eugene? Diga, para onde eu vou? [...] Sabe quantas mães empurraram suas filhas para ele? Sabe quantas pediram que ele engravidasse suas filhas, sem nem precisar se incomodar em pagar o preço de uma noiva? (ADICHIE, 2011, p. 264-265)

12 - Pare com essa gratidão. Se Eugene tivesse feito isso, a perda teria sido dele, não sua.

- Isso é o que você diz. Uma mulher com filhos e sem marido é o quê?

- Eu.

Mama balançou a cabeça.

- Lá vem você de novo, Ifeoma. Você sabe o que eu quis dizer, como uma mulher pode viver assim?

- perguntou Mama. Seus olhos estavam arregalados, ocupando mais espaço em seu rosto.

- Nwunye $m$, às vezes a vida começa quando o casamento acaba.
} 


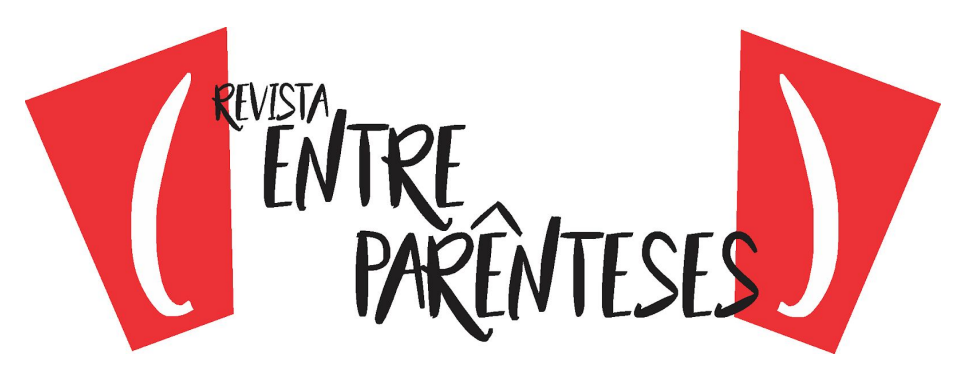

O discurso de Ifeoma para suas alunas era de emancipação, mesmo que algumas ao se casarem deixavam suas vidas nas mãos do marido. Por diversas vezes, como a própria menciona, ela procurou aconselhar alunas brilhantes para que lutassem pela sua independência, mas, de acordo com Ifeoma, elas acham que precisam de alguém que cuide delas, pois elas foram ensinadas dessa forma. Era esse discurso de valoração de si, com um parceiro ou não, que Ifeoma tentava incutir na cabeça de suas alunas e na de Beatrice.

Em um diálogo com seu pai, Papa Nnukwu, Ifeoma conta de seus problemas com a administração ditatorial da universidade e como as coisas estão difíceis. A reação de seu pai é esperar que um homem apareça para que possa prover para sua filha e seus netos uma vida sem necessidades, no entanto, Ifeoma tem outros planos para sua família.

"My spirit will intercede for you, so that Chukwu will send a good man to take care of you and the children."

"Let your spirit ask Chukwu to hasten my promotion to sênior lecturer, that is all I ask," Aunty Ifeoma said. (ADICHIE, 2011, p. 83)

Percebemos Ifeoma como uma mulher destemida, forte, que não tem medo de sua voz e de bater de frente com as pessoas sem se importar com as consequências. É independente financeiramente, mesmo passando por períodos ruins, professora universitária, viúva e com dois filhos. Acusada de assassinar o marido pela família do mesmo, não depende da família paterna de seus filhos, fazendo o possível para cria-los em um ambiente onde o diálogo é a principal arma.

\footnotetext{
- Você e essa conversa de universidade. É isso que você diz para suas alunas? - perguntou Mama, sorrindo (ADICHIE, 2011, p. 83)

13 - Meu espírito vai interceder em seu favor, para que Chukwu mande um bom homem para tomar conte de você e das crianças.

- Seu espírito que peça a Chukwu para acelerar minha promoção a professora sênior, é só isso que eu quero - disse tia Ifeoma. (ADICHIE, 2012, p. 92)
} 


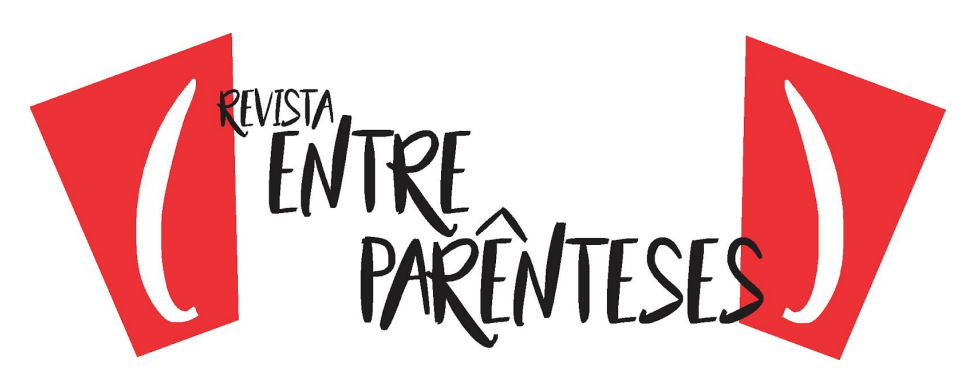

Ifeoma, apesar de ter se convertido ao cristianismo, não se comporta como o irmão Eugene. Enquanto este acredita que os que não são católicos são pagãos e pecadores e deixa seu pai idoso viver em condições precárias, mesmo dando tanto aos pobres desconhecidos que pedem ajuda, Ifeoma não admite discriminação por causa de religião, principalmente, no que dizia respeito a seu pai. Mesmo depois da morte de Papa Nnukwu, quando Eugene quer pagar um funeral católico, a mesma se nega veementemente e dá ao pai os ritos de sua religião.

Sem largar as práticas e costumes de seus ancestrais, Ifeoma entrou em conflito com Eugene diversas vezes, como ao insistir em chamar Beatrice de Nwunye $m$, que em igbo significa "minha esposa". O costume era que, ao se casar, a mulher não era esposa somente do marido, mas sim de toda a família. Eugene recriminava a irmã por essa atitude, porém sem resultados. Em discussões com o irmão, Ifeoma insistia em falar em igbo, mesmo que Eugene estivesse falando em inglês, o que fazia com que, muitas vezes, ele cedesse e, involuntariamente, começasse a falar em igbo também. O clima em seus encontros era sempre de tensão para Kambili, pois a menina não conseguia compreender como a tia não era obediente ao seu pai.

\footnotetext{
"Eugene," Aunty Ifeoma called out. "I was saying that Jaja annd Kambili should spend some time with me and the children tomorrow." Papa grunted and kept walking to the door. "Eugene!"

Every time Aunty Ifeoma spoke to Papa, my heart stopped, then started again in a hurry. It was the flippant tone; she did not seem to recognize that it was Papa, that he was different, special. I wanted to reach out and press her lips shut and get some of that shiny bronze lipstick on my fingers. (ADICHIE, 2011, p. 77)
}

\footnotetext{
${ }^{14}$ - Eugene - disse tia Ifeoma bem alto -, eu estava dizendo que Jaja e Kambili deviam passar algum tempo comigo e as crianças amanhã.

Papa soltou um grunhido e continuou andando até a porta.

- Eugene!

Toda vez que tia Ifeoma se dirigia a Papa, meu coração parava e depois começava a bater de novo, freneticamente. Era por causa daquele tom atrevido; ela não parecia reconhecr que aquele era Papa,
} 


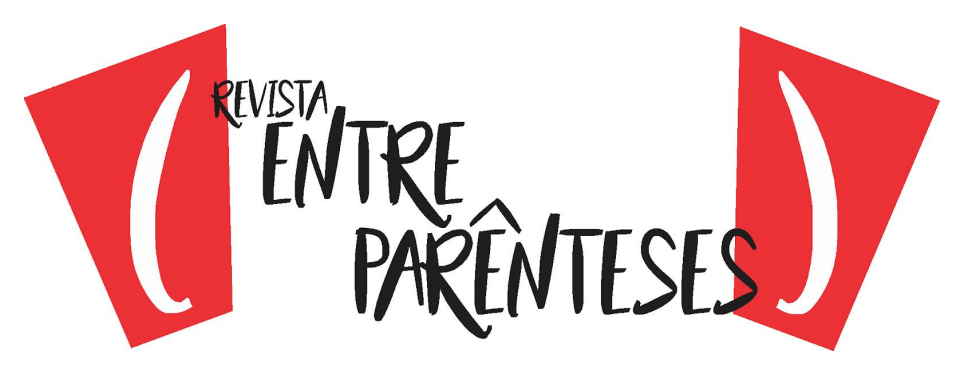

Ao mesmo tempo em que Kambili receava pela reação do pai e estranhava a falta de respeito da tia, observamos uma admiração ou uma vontade de ter um pouco do brilho da tia quando a narradora conta que pegar um pouco de seu batom bronze nos dedos.

Podemos perceber essa admiração de Kambili em relação a tia e constantes comparações entre Beatrice e Ifeoma. Para a narradora, a diferença entre as duas é sempre realçada quando estão juntas. Kambili observa o caminhar, tom de voz e até vestimentas. No diálogo descrito anteriormente, a narradora aponta que Beatrice tem os lábios pálidos em comparação aos de Ifeoma que estão cobertos com a cor bronze do batom.

Ao se identificar com a mãe, Kambili sente admiração pela prima, Amaka, como se ela fosse seu equivalente como sua tia é para a mãe. A narradora-personagem sente uma admiração pela prima ter sempre uma opinião e liberdade para expressá-la, pela relação que ela tem com o avô e pela sua aparência. Kambili se pergunta qual seria a sensação de ser destemida como a prima e usar aquela cor vermelha nos lábios, que deixa os dentes mais brancos.

[...] I did not stand in front of the mirror for too long, as Amaka did, because guilt would nibble at me. Vanity was a sin. [...] I took Amaka's lipstick from the top of the dresser and ran it over my lips. It looked strange, not as glamorous as it did on Amaka; it did not even have the same bronze shimmer. I wiped it off. My lips looked pale, a doour brown. I ran the ipstick over my lips again, and my hands shook. [...] I wiped the lipstick away with the back of my hand and left the room. (ADICHIE, 2012, p. 174)

que ele era diferente, especial. Tive vontade de apertar os lábios dela para fech=a-los, e também para pegar um pouco de batom cor de bronze nos dedos. (ADICHIE, 2012, p. 85-86)

${ }^{15}$ [...] não fiquei muito tempo na frente do espelho, como Amaka fazia, pois ia sentir a culpa me beliscando. A vaidade era pecado. [...] Peguei o batom de Amaka de cima da penteadeira e passei-o nos lábios. Ficou estranho, não tão glamuroso quanto ficava em Amaka; nem tinha o mesmo brilho cor de bronze. Esfreguei a boca para tirá-lo. Meus lábios ficaram pálidos, de um marrom sem graça. Passei o batom de novo, e minhas mão tremeram. [...] Tirei o batom com as costas da mão e saí do quarto. (ADICHIE, 2012, p. 185-186) 


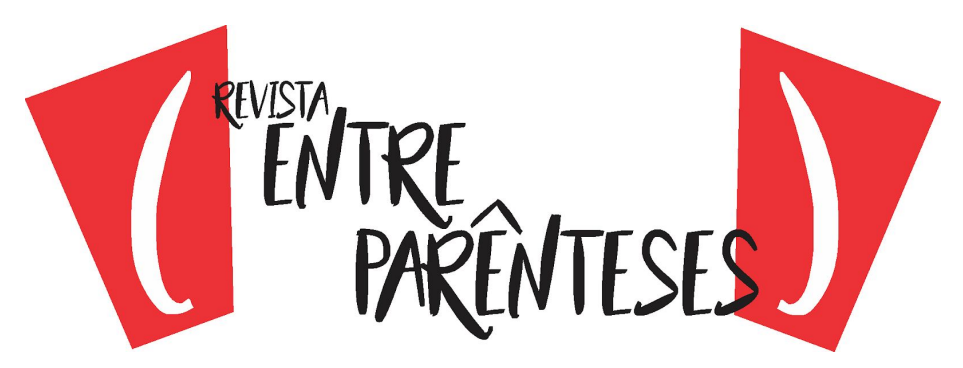

A narradora-personagem sente uma admiração e uma vontade de ser mais parecida com a prima, no entanto, várias forças a impedem: a presença constante do pai, mesmo que não fisicamente em alguns momentos; o medo de parecer estranha, como se aquilo não lhe pertencesse; e, o receio do que aquela atitude teria como consequência.

Após um primeiro momento de estranhamento entre as duas meninas, é na convivência com sua tia e primos que Kambili sai do papel de espectadora de sua vida. Ela aprende a se socializar, questionar e fazer amizades. Nisso, sua prima Amaka tem um papel fundamental nesse processo. Sendo uma menina que acompanhava as músicas, a arte e as gírias dos jovens nigerianos, Amaka mostra a Kambili uma outra possibilidade de ser. Aos poucos, na casa sem luxo de sua tia, Kambili descobre que a falta de energia e água dão lugar a um ambiente cheio de afeto e liberdade. Pois os tapetes persas, as mesas de vidro esboçam luxúria demais para um ambiente sem sentimentos como é a casa de seu pai.

A mensagem emancipadora está presente nas falas de Ifeoma e na forma que ela cria seus filhos. Em sua casa, um aspecto é extremamente importante e nunca falta, o diálogo. Ifeoma é uma mulher contestadora que incentiva os filhos a terem liberdade de expressão e poder de articulação, o que deixa Kambili impressionada. Acostumada a uma convivência familiar baseada no silêncio e em orações, a personagem-narradora se assusta ao presenciar as conversas na hora das refeições e as diferentes opiniões coabitando com facilidade.

Esse incentivo ao diálogo, que é constantemente motivado, opera mudanças valiosas em Kambili. O silêncio, tão presente em sua casa, passa a adquirir nova forma depois de sua temporada em Nsukka, na casa da tia. A configuração das vozes das personagens são marcantes e caracterizam a personalidade de cada uma delas. 


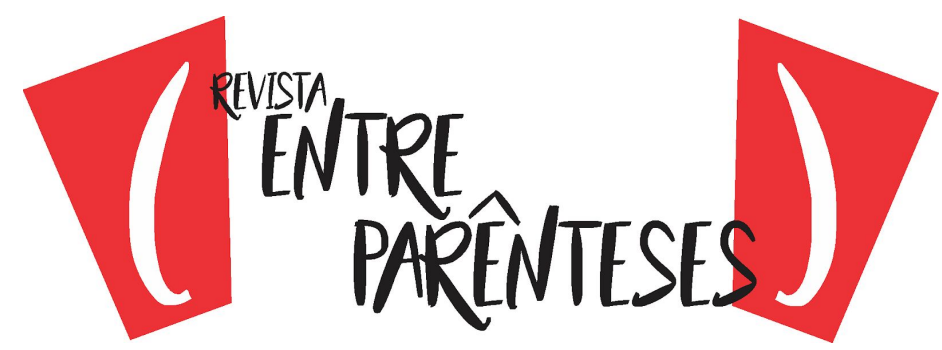

\section{CONSIDERAÇÕES FINAIS}

Em Purple Hibiscus, percebe-se a trajetória feita por Kambili na construção de sua identidade, pois ela sai de um núcleo onde o elo central é o colonizado pai para um ambiente livre. Eugene é um exemplo da violência que a colonização foi para muitos indivíduos. Sem reconhecer sua história, seus ancestrais, seu idioma, o sujeito passa pelo processo de aculturação ao se deparar com uma autoestima destruída. Não lhe sobra muito a não ser tentar embranquecer-se ou desaparecer, como sugere Fanon. Purple Hibiscus nos mostra os efeitos da colonização branca da África e de como muito mais do que a economia sofreu com isso. Mesmo tentando de todas as formas ser um senhor inglês, Eugene nunca será um, mas também não é um autêntico pertencente a tribo igbo. $O$ processo de colonização fez com que Eugene não pudesse fazer parte nem de um grupo nem de outro.

Além disso, observa-se que os estudos de gênero estão em constante problematização. O que se verifica é uma tentativa de livrar-se das amarras impostas socialmente para uma cadeia de estruturas múltiplas livres de dicotomias e binarismo. As identidades de gêneros aprisionam o sujeito, pois elas se tornam estilos normativos de vida.

O feminismo pós-moderno tem como ponto mais importante a valorização das diferenças raciais, econômicas, etárias e etc. Tentando criar novos termos e uma linguagem que reflita melhor as experiências das mulheres, observa-se ser impossível falar de uma categoria única que possa ser enquadrada como foco do movimento feminista e como detentora das necessidades principais e lutas a serem combatidas. O feminismo negro buscou uma solução para essa questão da falta de reconhecimento nas categorias defendidas. Muito se estudou e aprofundou no tema, possibilitando que muitas mulheres se vissem contempladas e sentissem como se suas vozes tivessem sido recuperadas. 


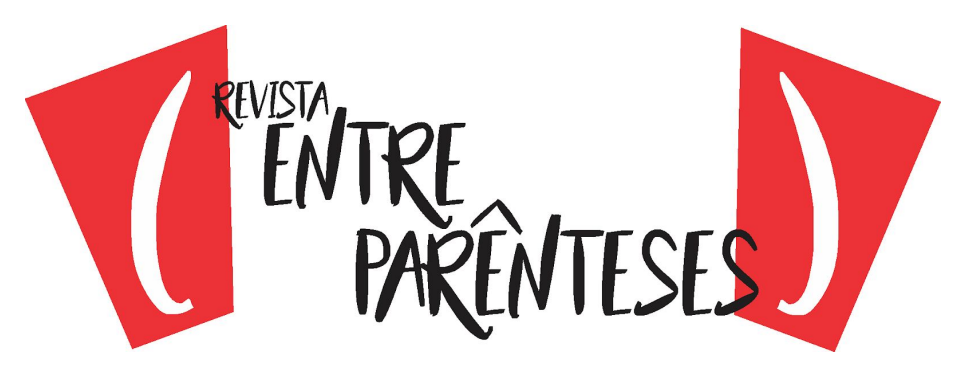

A obra se encerra com muitas mudanças na vida de Kambili e de seus familiares mais próximos. Seu irmão decide assumir a culpa pelo que aconteceu com pai em uma tentativa de proteger sua família. Kambili vê em seu futuro e no de sua família a esperança de dias melhores. Faz planos para plantar hibiscos roxos em sua nova casa, longe de todas as lembranças ruins e como um sinal de um futuro promissor.

Por sua vez, Beatrice mostra-se ativa, diferente da mulher submissa e resignada do início do romance. Após ter invenenado o marido para livrar a si e seus filhos do julgo dele, ela se reinventa mudando de endereço, de corte de cabelo e de comportamento. A vida segue após os fatos e todos reconstroem sua vida, dessa vez sem a violência de Eugene. A autora em momento algum a condena em seu texto ou a justifica. Isso fica a cargo do leitor.

Com isso, concluímos que Ifeoma e Beatrice, embora diferentes entre si, se mostram mulheres lutadoras, cada uma a seu modo. As formas de resistência escolhida por cada uma mostram a complexidade do ser mulher e de todos os aspectos que precisam ser levados em consideração ao tentar encaixar a mulher em uma categoria.

Percebemos que Chimamanda Ngozi Adichie, como uma boa contadora de histórias, consegue expressar uma parte das especificidades da mulher nigeriana, bem como mostrar sua força. Adichie é uma oradora eloquente e precisa, que consegue usar a linguagem para tratar de assuntos que, infelizmente, ainda são de difícil abertura para muitos. A feminista feliz que não tem medo de homens e é vaidosa, como ela mesmo se intitula, consegue construir uma narrativa onde simpatizamos com a psicologia de cada personagem feminina, pela sua força, resistência e lutas contra os opressores diversos.

Em sua palestra "The danger of a single story" temos uma passagem importante que representa o caráter didático das histórias contadas por seus ancestrais e agora por ela e outros escritores nigerianos. Para a autora, todas as 


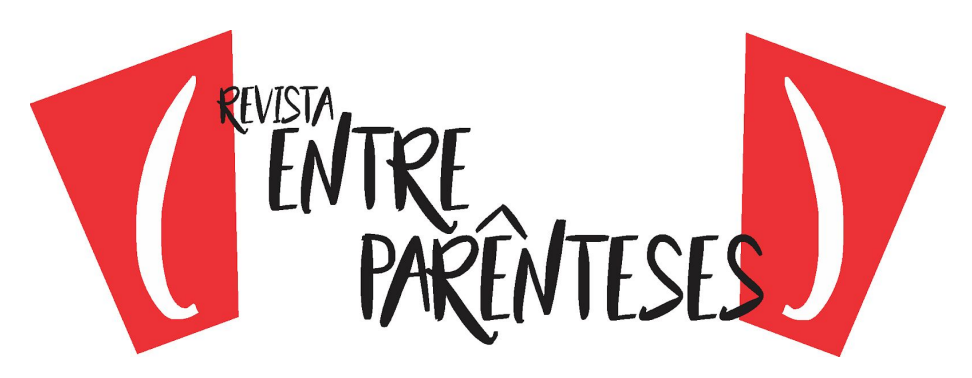

histórias importam. "Stories have been used to dispossess and to malign, but stories can also be used to empower and to humanize. Stories can break the dignity of a people, but stories can also repair that broken dignity". ${ }^{16}$ Essa devolução da dignidade às mulheres negras, no caso desse romance, é o que se espera com a conclusão desse trabalho.

\section{REFERÊNCIAS}

ACHOLONU, C. (1995). Afrocentric alternative to feminism In ARNDT, S. (2002) The Dynamics of African Feminism. Defining and Classifying African Feminist Literatures, Africa World Press: Trenton.

ADICHIE, C. N. Hibisco roxo. Trad. Julia Romeu. SP: Companhia das letras, 2011.

ADICHIE, C. N. Purple Hibiscus. North Carolina: Algonquin, 2003

ADICHIE, C. N. The Danger of a single story. Disponível em: <http://www.ted.com/talks/chimamanda_adichie_the_danger_of_a_single_story/> Acesso em: 12 de junho de 2018.

COLEMAN, M. A. Ain't I a feminist too? Third wave womanist religious thought. Minneapolis: Fortress Press, 2013.

DAVIS, A. Mulheres, raça e classe. Trad. Heci Regina Candiani. SP: Boitempo, 2016

DAVIS, A. Mulheres, cultura e política. Trad. Heci Regina Candiani. SP: Boitempo, 2017

MULLER, F. de O. O florescer das vozes na tradução de Purple Hibiscus, de Chimamanda Ngozi Adichie. Brasília: Unb, 2017.

OGUNDIPE-LESLIE, M. Re-creating Ourselves. African Women \& Critical Transformations, Africa World Press: Trenton, 1994.

\footnotetext{
${ }^{16}$ Histórias têm sido usadas para expropriar e tornar maligno. Mas histórias também podem ser usadas para capacitar e humanizar. Histórias podem destruir a dignidade de um povo, mas histórias também podem reparar essa dignidade perdida. (Tradução nossa)
} 


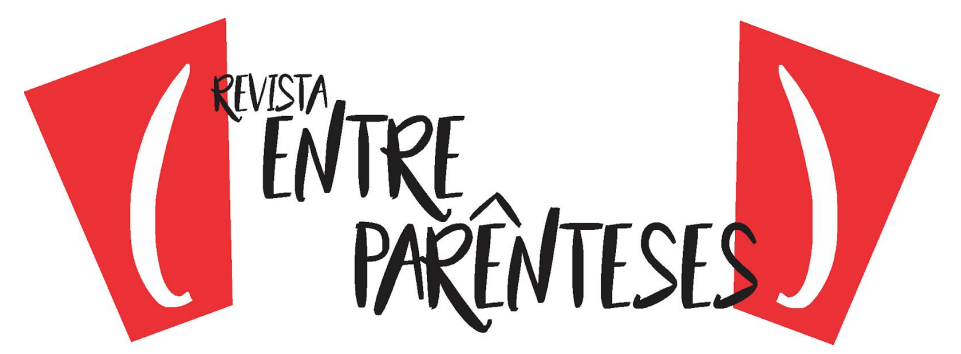

OGUNYEMI, C.O. Women and Nigeria Literature. In Y. Ogunbiy (Ed.). Perspectives on Nigerian literature (pp. 60-67). Lagos: Guardian Books, 1988.

WALKER, ALICE. In search of our mother's gardens. London: The Women's Publishers, 1972.

ZINANI, Cecil Jeanine Albert. Literatura e Gênero. A construção da identidade feminina. Caxias do Sul, RS: Educs, 2013.

Recebido em: 22/04/2019

Aceito em: 27/01/2020 